\title{
Control of Hexagonal Modular Multilevel Converter for 3-phase BTB System
}

\author{
Shin-ichi Hamasaki, Kazuki Okamura, Takashi Tsubakidani, Mineo Tsuji \\ Division of Electrical Engineering and Computer Science, \\ Nagasaki University, \\ Nagasaki, Japan \\ hama-s@nagasaki-u.ac.jp
}

\begin{abstract}
The Modular Multilevel Converter (MMC) with cascaded full bridge cells is available for AC/AC transmission system without transformers in high voltage line. This research applied a Hexagonal MMC (H-MMC) to 3-phase AC-AC back-to-back (BTB) system. The H-MMC has six arm modules with floating capacitors and is required to regulate the input-output power and capacitor voltages by controlling currents in arm modules. Theory of the power flow of H-MMC is analyzed and the control scheme of the power flow and capacitor voltage regulation is proposed. Currents in the arm modules are controlled by the internal model principle and H-MMC can operate appropriately. Effectiveness of the proposed control method is presented in simulation and experiment.
\end{abstract}

Keywords- modular multilevel converter, AC/AC converter, back to back system, power flow control

\section{INTRODUCTION}

In recent years, energy conservation problems have been important due to $\mathrm{CO}_{2}$ emission, abandoning nuclear generation and so on. In such situation, renewable energy systems have been focused and a lot of photovoltaic and wind power generation systems have introduced all over the world. However renewable energy generations give influence of voltage fluctuation to power grid because of their unstable output and reverse power flow. Therefore it is important to maintain the voltage of power line. This importance will increase by promotion of the electricity liberalization. In general, $\mathrm{AC} / \mathrm{AC}$ transmission system is introduced for power flow control. Many kinds of $\mathrm{AC} / \mathrm{AC}$ system such as back-to-back (BTB) system, cycloconverter and matrix converter are developed and investigated.

On the other hands, several kinds of multilevel converter for high voltage and less harmonics are investigated. Conventional multilevel converter has transformers on DC bus, which is one of the reasons of heavy and large system. A modular multilevel converter (MMC)[1]-[9] is one of the transformer-less converter and applies to high voltage and high power conversion. The MMC consists of cascaded switching device modules with floating capacitors.

The multilevel converter such as the MMC can improve waveform and reduce harmonics by multilevel voltage output. The triple star type MMC[6] and the hexagonal type MMC[7][8] are constructed as a 3-phase $\mathrm{AC} / \mathrm{AC}$ converter. The hexagonal MMC (H-MMC) can be applied to power flow control system instead of BTB system. In addition, this is less flexibility than the triple star type MMC and conventional multilevel BTB system, but is able to realize to reduce a number of cells compared with those systems. This H-MMC topology is expected for a wide range of fields such as a wind power converter, a grid connection converter and high voltage motor drive.

In this paper, $\mathrm{H}-\mathrm{MMC}$ is investigated and applied to BTB system for a power flow controller. Theory of the power flow of H-MMC is analyzed and the control scheme of the power flow and capacitor voltage regulation for H-MMC is proposed. Effectiveness of the proposed control is shown by simulation and experiment in typical cases.

\section{CONFIGURATION OF CIRCUIT}

Fig. 1 shows the configuration of H-MMC. The HMMC has 6 arm-modules connected in hexagonal ring shape. These modules consist of multiple cascade full bridge cells which have floating capacitors. Each arm module has a buffer reactor for preventing short circuit and current regulation. The number of cells in an armmodule is 2 as shown in Fig.1(a). Number of these can be increased depending on usage situation. In Fig.1(a), terminals of R,S,T are primary side of power line and terminals of $\mathrm{U}, \mathrm{V}, \mathrm{W}$ are secondary side. Primary power via $\mathrm{R}, \mathrm{S}, \mathrm{T}$ can be flowed to floating capacitors and secondary side via UVW. This configuration means that RST-delta connection and UVW-delta connection overlap each other. Thus each arm module has primary and secondary line-to-line current.

The power on primary side, the power on secondary side and all the voltages of floating capacitors in cells are required to regulate by controlling output of the modules. When the arm current is controlled in case of different frequencies between primary and secondary side, it is necessary that two frequency components are controlled at the same time. In this research, the internal model principle is applied to the current control to obtain a good current regulation. 


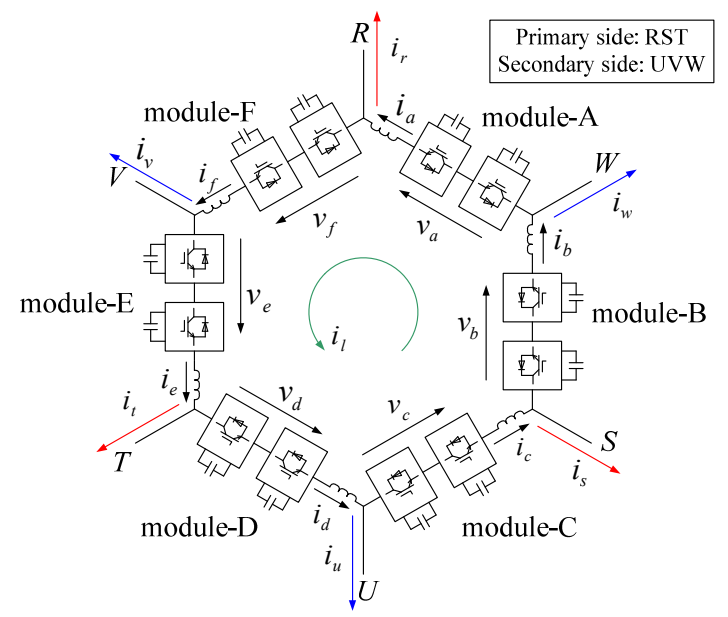

(a) Summary of H-MMC circuit

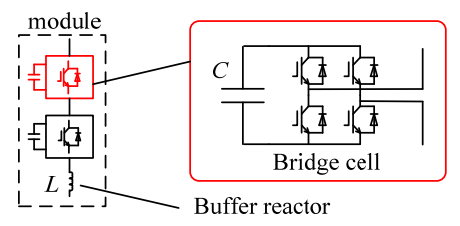

(b) Configuration of module and cell

Fig. 1. Circuit configuration of H-MMC

\section{Control of HeXagonal type MMC}

When H-MMC is applied to a power converter, it is able to convert frequency and voltage arbitrarily without transformer. At this time, currents of each arm module must be controlled to be non-sinusoidal waveform, which is due to overlap line-to-line currents of primary and secondary. It is important that every capacitor voltage is managed to be constant and arm currents are exactly controlled without steady state error. In this study, capacitor voltages are kept by current control based on analysis the power flow in H-MMC. When the line-to-line current $i_{r s}$ is current for primary node $R-S$ and the line-to-line current $i_{v w}$ is current for secondary node $X-Y$, current of armmodule A is calculated in (1).

$$
i_{a}=i_{r s}+i_{w w}
$$

Other currents of modules are obtained the same as (1).

\section{A. $P Q$-coordinate transformation}

The control of primary and secondary power is realized by the pq-coordinate transform. In particular, the primary power control is handled in the pq-current in order to regulate all the floating capacitor voltages. Thereafter the pq-quantity is transformed to 3-phase quantity and the primary 3-phase currents are controlled together with the secondary 3-phase currents by the arm modules.

The pq-transform is defined as following equation.

$$
\left[\begin{array}{l}
F_{p} \\
F_{q}
\end{array}\right]=\sqrt{\frac{2}{3}}\left[\begin{array}{ccc}
\sin \omega_{0} t & \sin \left(\omega_{0} t-\frac{2 \pi}{3}\right) & \sin \left(\omega_{0} t-\frac{4 \pi}{3}\right) \\
\cos \omega_{0} t & \cos \left(\omega_{0} t-\frac{2 \pi}{3}\right) & \cos \left(\omega_{0} t-\frac{4 \pi}{3}\right)
\end{array}\right]\left[\begin{array}{l}
f_{u} \\
f_{v} \\
f_{w}
\end{array}\right]
$$

,where $F_{p}$ and $F_{q}$ are active and reactive component respectively. $f_{u}, f_{v}$ and $f_{w}$ are 3-phase components. $\omega_{0}$ is an angular frequency the same as $u, v, w$-phase one.

\section{B. Power flow control in secondary side}

Power in secondary side can be controlled to arbitrarily value by using the pq-theory. The pq currents in secondary side are converted to 3-phase line-to-line currents with voluntary frequency, which are controlled by the arm modules.

\section{Power flow control in primary side}

Power in primary side can be controlled in accordance with the secondary power by the pq-theory. In this control, however, the primary power is also controlled to maintain each capacitor voltage. The pq-current references in primary side are calculated from capacitor voltages in modules because there is relevance between the primary power and the capacitor voltage. Then power flows involved in arm-modules are analyzed. The average power of each arm-module is constructed by overlap of primary and secondary power, which is defined as $P_{A}$, $P_{B}, P_{C}, P_{D}, P_{E}$ and $P_{F}$, respectively. These average powers are calculated by the following equations.

$$
\begin{aligned}
P_{A C E} & =P_{A}=P_{C}=P_{E} \\
& =\frac{V_{1} I_{1}}{\sqrt{3}} \cos \left(\phi_{1}-\frac{\pi}{6}\right)-\frac{V_{2} I_{2}}{\sqrt{3}} \cos \left(\phi_{2}-\frac{5 \pi}{6}\right) \\
P_{B D F} & =P_{B}=P_{D}=P_{F} \\
& =-\frac{V_{1} I_{1}}{\sqrt{3}} \cos \left(\phi_{1}-\frac{5 \pi}{6}\right)+\frac{V_{2} I_{2}}{\sqrt{3}} \cos \left(\phi_{2}-\frac{\pi}{6}\right)
\end{aligned}
$$

,where $V_{1}$ and $I_{1}$ are RMS volumes in primary side, $V_{2}$ and $I_{2}$ are RMS volumes in secondary side. $\phi_{1}$ is the power factor angle in primary side, and $\phi_{2}$ is the power factor angle in secondary side.

And the average power is calculated by (5).

$$
\begin{aligned}
& P_{X}=\frac{1}{T} \int_{t-T}^{t} p_{x} d t=\frac{1}{T} \int_{t-T}^{t} v_{x} i_{x} d t \\
& (X=A-F, x=a-f)
\end{aligned}
$$

(3) and (4) show that modules A,C,E and modules B,D,F have the same average power $P_{A C E}$ and $P_{B D F}$ respectively. Following equations show sum of $P_{A C E}$ and $P_{B D F}$.

$$
P_{A C E}+P_{B D F}=V_{1} I_{1} \cos \phi_{1}+V_{2} I_{2} \cos \phi_{2}
$$

(6) shows the fluctuation of energy in H-MMC. If (6) is positive, all the capacitor voltages increase because the energy is stored in H-MMC. Otherwise, all the capacitor voltages decrease because the energy is emitted from $\mathrm{H}$ MMC. Therefore, it is desirable that (6) is maintained to 0 in order to operate H-MMC exactly at steady state. In this case, (7) is obtained. 


$$
V_{1} I_{1} \cos \phi_{1}=-V_{2} I_{2} \cos \phi_{2}
$$

(7) means that input active power in primary side is equal to the output active power in secondary side. When (7) is satisfied, the average voltage of all the capacitors is maintained to be constant.

From the above, the average value of all capacitor voltage is controlled by the primary active power, and the average power difference is controlled by the primary reactive power respectively. The following control strategies are given by considering relevance between capacitor voltage and average power.

$$
I_{p 1}^{*}=\left(K_{P 1}+\frac{K_{I 1}}{s}\right)\left(\bar{v}_{C}-v_{C}^{*}\right)-\frac{V_{2}}{V_{1}} I_{p 2}^{*}
$$

,where $\bar{v}_{C}$ is average value of all the capacitor voltages. In (8), first term of right-hand side means PI control of capacitor voltage and second term means feed-forward term depending on the active power in secondary side. On the other hand, $I_{q 1}{ }^{*}$ is given voluntarily. In usual, $I_{q 1}{ }^{*}$ is set to 0 in order to keep the power factor 1 . The pq-currents are converted to three-phase currents and determine the line-to-line currents in primary side.

\section{Loop current control}

The power control on primary side is able to balance the capacitor voltages between modules A, C, E and B, D, $\mathrm{F}$. Voltage balance in all the arm-modules is realized by a loop current control. The loop current has two frequencies of primary side and secondary side. The loop current can be calculated in (9).

$$
i_{l}=\left(i_{a}+i_{b}+i_{c}+i_{d}+i_{e}+i_{f}\right) / 6
$$

The loop current can be separated in three components First one is current depending on primary current, second one is current depending on secondary current and the last is pure loop current in the ring of H-MMC.

The first loop current reference is given by the following equation.

$$
\begin{aligned}
i_{l 1}^{*}= & -K_{L}\left(\bar{v}_{C}-\bar{v}_{C-R S}\right) \sin \omega_{1} t \\
& -K_{L}\left(\bar{v}_{C}-\bar{v}_{C-S T}\right) \sin \left(\omega_{1} t-\frac{2}{3} \pi\right) \\
& -K_{L}\left(\bar{v}_{C}-\bar{v}_{C-T R}\right) \sin \left(\omega_{1} t+\frac{2}{3} \pi\right)
\end{aligned}
$$

,where $\omega_{1}$ is primary side angular frequency and $\bar{v}_{C-X Y}(X$, $Y=R, S, T)$ is average of capacitor voltages between node $X$ and $Y$. For example, $\bar{v}_{C-R S}=\left(\bar{v}_{C A}+\bar{v}_{C B}\right) / 2$ is derived from Fig.1.

The second loop current reference is given by the following equation.

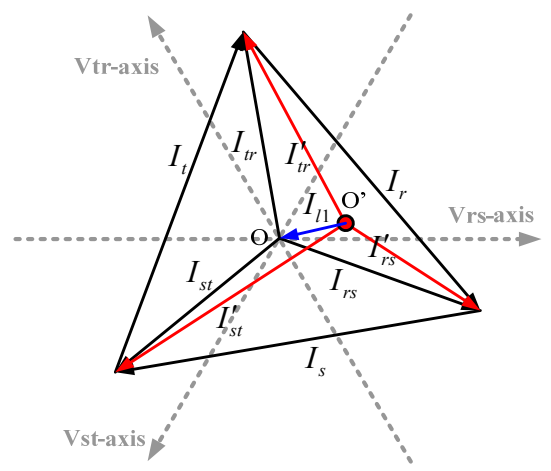

Fig. 2. current vector plot (in primary side)

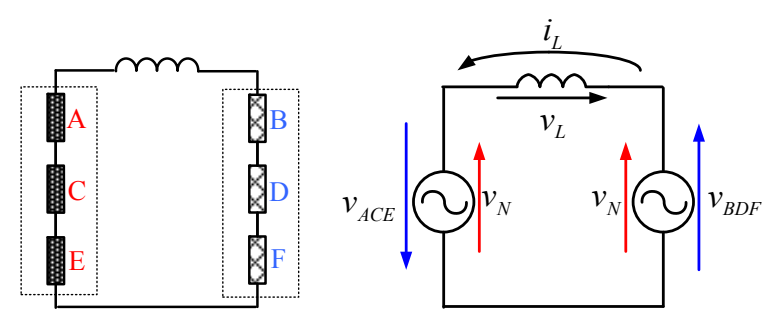

Fig. 3. Equivalent circuit for pure loop current control.

$$
\begin{aligned}
i_{l 2}^{*}= & -K_{L}\left(\bar{v}_{C}-\bar{v}_{C-U V}\right) \sin \omega_{2} t \\
& -K_{L}\left(\bar{v}_{C}-\bar{v}_{C-V W}\right) \sin \left(\omega_{2} t-\frac{2}{3} \pi\right) \\
& -K_{L}\left(\bar{v}_{C}-\bar{v}_{C-W U}\right) \sin \left(\omega_{2} t+\frac{2}{3} \pi\right)
\end{aligned}
$$

,where $\omega_{2}$ is secondary side angular frequency and $\bar{v}_{C-X Y}(X, Y=U, V, W)$ is average of capacitor voltages between node $X$ and $Y$. For example, $\bar{v}_{C-U V}=\left(\bar{v}_{C D}\right.$ $\left.+\bar{v}_{C E}\right) / 2$ is derived from Fig. 1 .

Fig. 2 shows a current vector plot at the case. This figure shows the primary side and the same principle can be applied to the secondary side. By the loop current control, the neutral point is intentionally displaced by (10) and (11). The displaced difference of the neutral point is the same as the loop current. In this way, the loop current control can adjust voltage balance among modules by unbalancing three-phase line-to-line current. Note that this unbalance affects only line-to-line current in $\mathrm{H}$ MMC. It means that phase currents of before and after the conversion are not affected by this unbalance.

In addition to the above controls, pure loop current control between modules is introduced. This scheme is able to accommodate active power between modules A, C, E and B, D, F.

Fig. 3 shows an equivalent circuit between modules $\mathrm{A}$, C, E and modules B, D, F. Sum of voltages of A, C, E and voltages of $\mathrm{B}, \mathrm{D}, \mathrm{F}$ are regarded as voltage source $v_{A C E}$ and $v_{B D F}$ respectively. This is assumed for pure loop current control. To obtain circulate current in ring of $\mathrm{H}$ $\mathrm{MMC}$, additional current and voltage references are given in (12) and (13) respectively.

$$
i_{L}^{*}=K_{D I}\left(v_{C_{-} B D F}-v_{C_{-} A C E}\right)
$$




$$
v_{L}^{*}=\left|K_{D V}\left(v_{C_{-} B D F}-v_{C_{-} A C E}\right)\right|
$$

The total loop current reference is calculated by (14).

$$
i_{l}^{*}=i_{l 1}^{*}+i_{l 2}^{*}+i_{L}^{*}
$$

(14) is added to current reference of each arm module and (13) is added to voltage reference of arm module $\mathrm{B}, \mathrm{D}, \mathrm{F}$ and subtracted to voltage reference of arm module A,C,E.

\section{E. Internal model principle}

Power conversion and module voltage balance are controlled by regulating currents in H-MMC. Currents of modules are expressed by the following equations.

$$
i_{a}^{*}=i_{r s}^{*}+i_{v w}^{*}+i_{l}^{*}
$$

Other current references of modules are obtained the same as (15). Each module current has both frequencies in primary and secondary side. Therefore it is difficult to regulate the current of arm-modules accurately.

In this research, the module current is directly controlled by applying the internal model principle. The internal model principle has a merit that the applied controller can realize current control without steady error. It is defined that the transfer function of control system has mathematical model of reference signal. $G_{C}(s)$ is the transfer function of controller which includes two sinusoidal function models.

$$
G_{C}(s)=\frac{K_{S c 1} s}{s^{2}+\omega_{1}^{2}}+\frac{K_{S c 2} s}{s^{2}+\omega_{2}^{2}}
$$

Based on (16), Control strategy of current controller of each module is shown in (17).

$$
\begin{aligned}
v_{x}^{*} & =K_{P c}\left(i_{x}^{*}-i_{x}\right) \\
& +\left(\frac{K_{S c 1} \omega_{1}^{2} s}{s^{2}+2 \zeta \omega_{1} s+\omega_{1}^{2}}+\frac{K_{S c 2} \omega_{2}^{2} s}{s^{2}+2 \zeta \omega_{2} s+\omega_{2}^{2}}\right)\left(i_{x}^{*}-i_{x}\right) \\
& (x=a-f)
\end{aligned}
$$

First term in the right side is a proportional control, and second term is a control of the internal model principle with damping. The damping coefficient is valid at transient, but is 0 in steady state. The controller has sinusoidal internal model of primary and secondary frequencies.

\section{$F$. Voltage balance in each module}

Voltage balance in each module is introduced[1]. Because unbalance in each arm module occurs due to variations of individual differences of capacitance, switching delay and so on. The balancing control is given by (18).

$$
\begin{aligned}
v_{B-x n}^{*} & =-K_{B}\left(\bar{v}_{C x}-v_{C-x n}\right) i_{x} \\
\bar{v}_{C x} & =\frac{\sum_{n=1}^{N} v_{C-x n}}{N}
\end{aligned}
$$

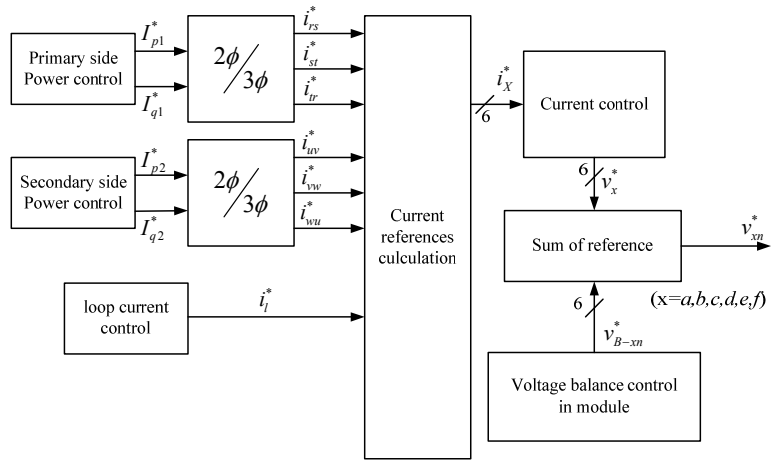

Fig. 4. Configuration of total control system

where (19) is average value of cell capacitor voltages in an arm module and $N$ is the number of cells. $v_{C-x n}$ is capacitor voltage, $v_{B-x n}^{*}$ is voltage reference value for balancing capacitor voltage in each module. Index ' $-x n$ ' means $n$-th cell in $x$-module. This control can adjust voltage balance among cells in an arm module because of exchange of power among cells. Voltage reference values in (13), (17) and (18) are summed up and output from each cell.

The configuration of overall control system is shown in Fig.4.

\section{Simulation}

Simulation is performed to verify the proposed control methods by using interconnection circuit of power line in Fig.5. Table I shows the parameters of the circuit, and table II shows the control gains. In this research, the $\mathrm{H}-\mathrm{MMC}$ has 2 full-bridge cells per an arm module, and each cell is operated the uni-pole PWM switching with shifted triangular wave of which phase is shifted according to the number of modules. The line voltage becomes 9-levels in case of 4 cells in line-to-line modules. The HMMC can realize multilevel voltage output by this PWM switching pattern.

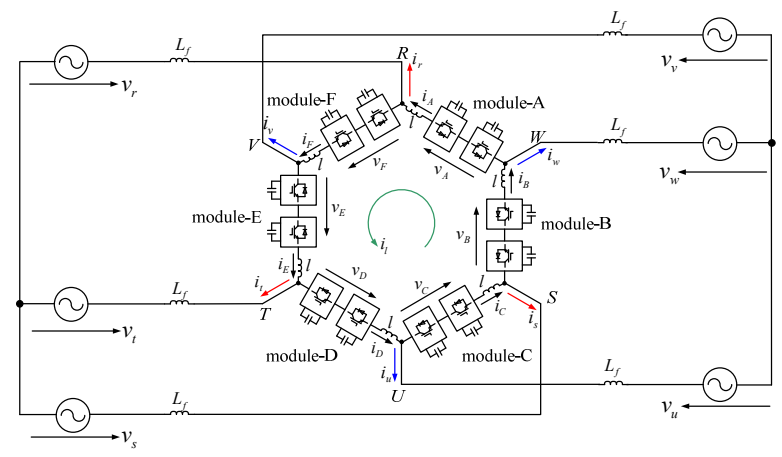

Fig. 5. Simulation circuit

TABLE I

PARAMETERS OF CIRCUIT

\begin{tabular}{|c|c|c|c|}
\hline$V_{1}$ & $200 \mathrm{Vrms}$ & $V_{2}$ & $200 \mathrm{Vrms}$ \\
\hline$l$ & $5 \mathrm{mH}$ & $C$ & $5000 \mu \mathrm{F}$ \\
\hline$v_{c}{ }^{*}$ & $200 \mathrm{~V}$ & $L_{f}$ & $3 \mathrm{mH}$ \\
\hline
\end{tabular}



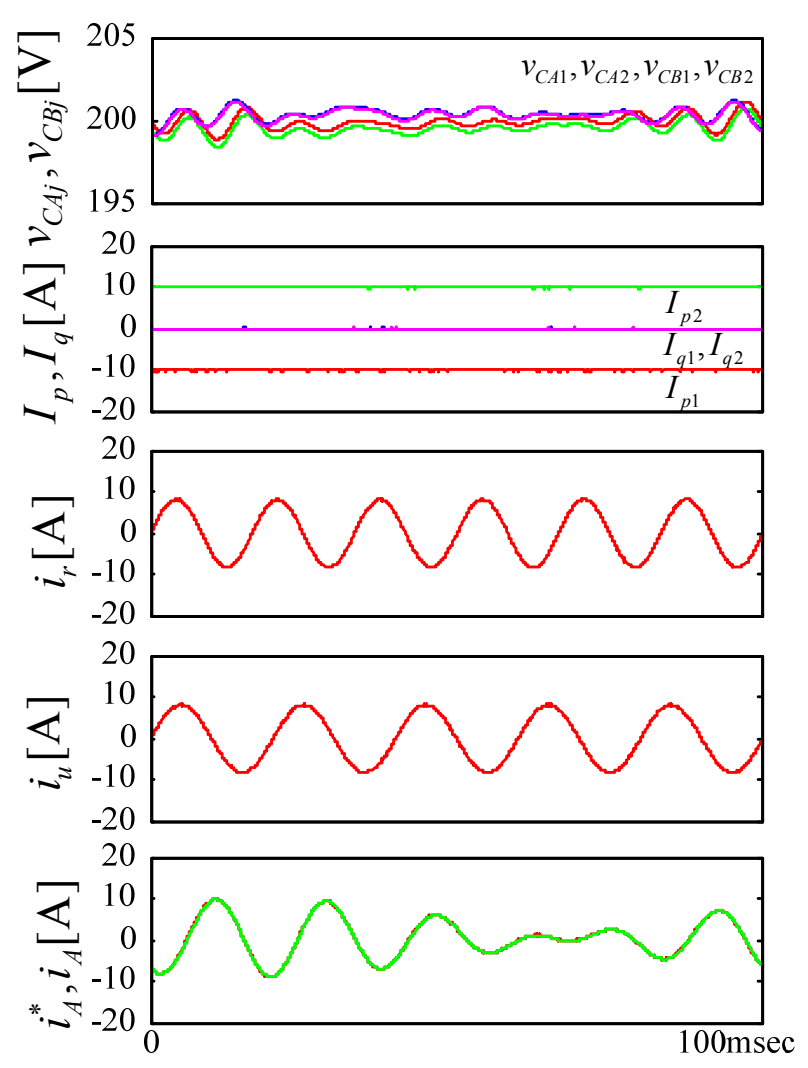

Fig. 6. Simulation result $\left(f_{1}: 60 \mathrm{~Hz}, f_{2}: 50 \mathrm{~Hz}\right)$

TABLE II

GAINS OF CONTROL

\begin{tabular}{|c|c|c|c|}
\hline$K_{P 1}$ & 1.5 & $K_{I 1}$ & 5.0 \\
\hline$K_{S \mathrm{c} 1}$ & 0.1 & $K_{S \mathrm{c} 2}$ & 0.1 \\
\hline$K_{P \mathrm{c}}$ & 40 & $K_{L}$ & 0.5 \\
\hline$K_{D I}$ & 1.5 & $K_{D V}$ & 15 \\
\hline$K_{B}$ & 0.1 & \multicolumn{3}{|c|}{} \\
\hline
\end{tabular}

Fig.6 shows a simulation result that input frequency is $60 \mathrm{~Hz}$ and output frequency is $50 \mathrm{~Hz}$. It is confirmed that $I_{p 1}$ and $I_{p 2}$ are the same absolute value $10 \mathrm{~A}$ but opposite sign at steady state. This means that received active power of H-MMC from primary side is the same value as the supplied active power to secondary side. Average voltage of all floating capacitors is maintained to be constant value around $200 \mathrm{~V}$. On the other hand, current of primary side, secondary side and arm module can be outputted accurately. Especially, current of arm module is precisely regulated by the internal model principle in spite of mixed frequency.

Fig. 7 shows a simulation result that input frequency is $60 \mathrm{~Hz}$ and output frequency is $10 \mathrm{~Hz}$. The good result is obtained like Fig.6. These simulation results show that $\mathrm{H}-$ MMC is able to convert exactly regardless of frequency and voltage. The H-MMC can be applied to grid connection converter as a power flow controller and a power conditioner for wind generators.
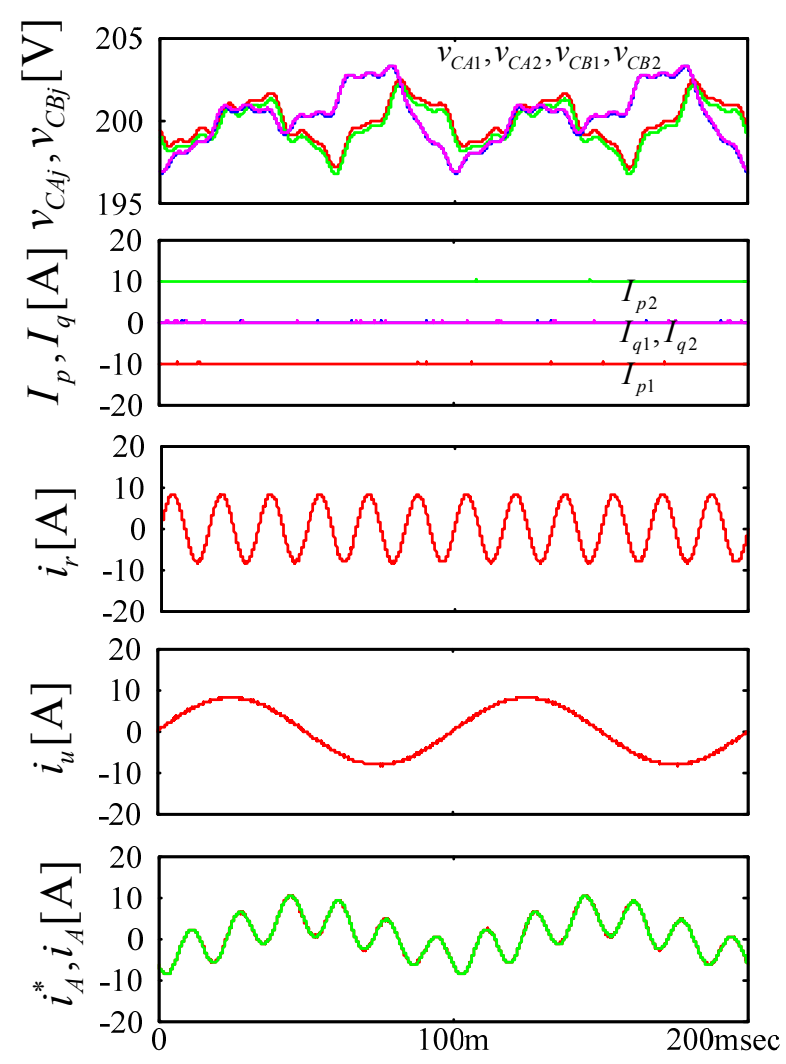

Fig. 7. Simulation result $\left(f_{1}: 60 \mathrm{~Hz}, f_{2}: 10 \mathrm{~Hz}\right)$

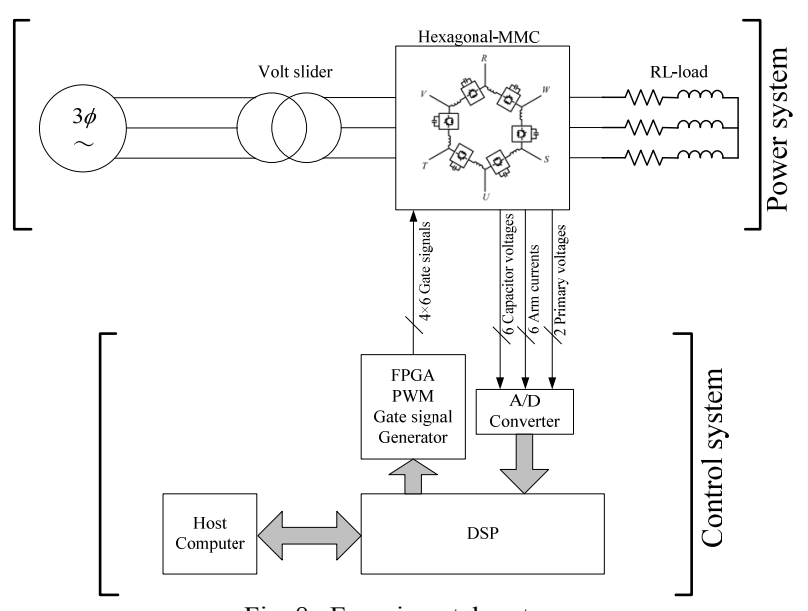

Fig. 8. Experimental system

TABLE III

PARAMETERS OF EXPERIMENTAL CIRCUIT

\begin{tabular}{|c|c|c|c|}
\hline$V_{1}$ & $12 \mathrm{Vrms}$ & $V_{2}$ & $12 \mathrm{Vrms}$ \\
\hline$l$ & $1.5 \mathrm{mH}$ & $C$ & $3300 \mu \mathrm{F}$ \\
\hline$R$ & $22 \Omega$ & $L$ & $10 \mathrm{mH}$ \\
\hline$v_{C}{ }^{*}$ & $30 \mathrm{~V}$ & \multicolumn{3}{|}{} \\
\hline
\end{tabular}

\section{EXPERIMENT}

Experimental system is constructed for a basic test of H-MMC as shown in Fig.8. This system has single cell per arm module and power scale of circuit is small in Table III. All the controls are executed by the DSP (TI : TMS320C6713-225) and PWM of the shifted triangular 

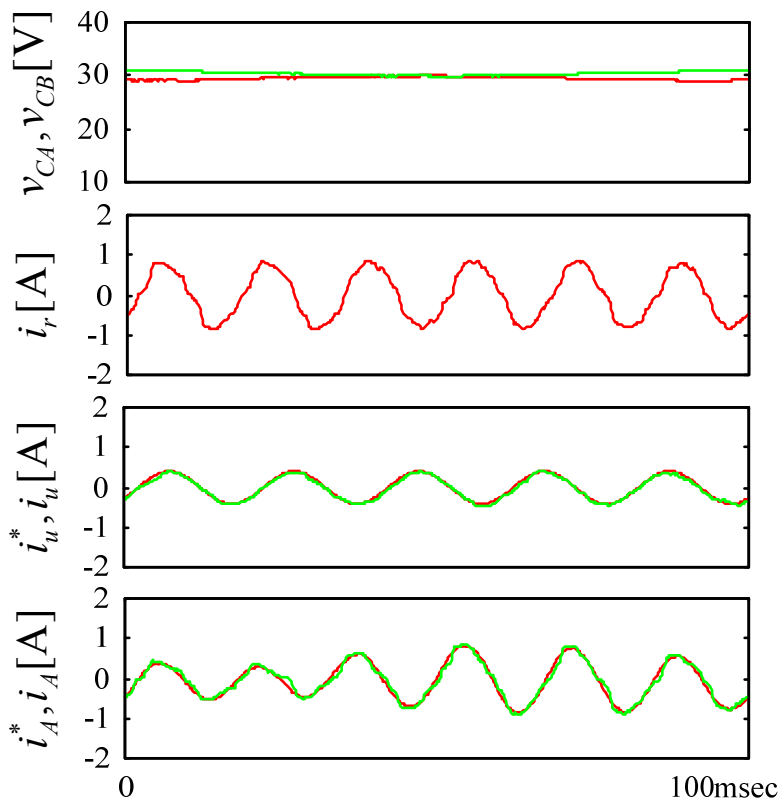

Fig. 9. Experimental result $\left(f_{1}: 60 \mathrm{~Hz}, f_{2}: 50 \mathrm{~Hz}\right)$
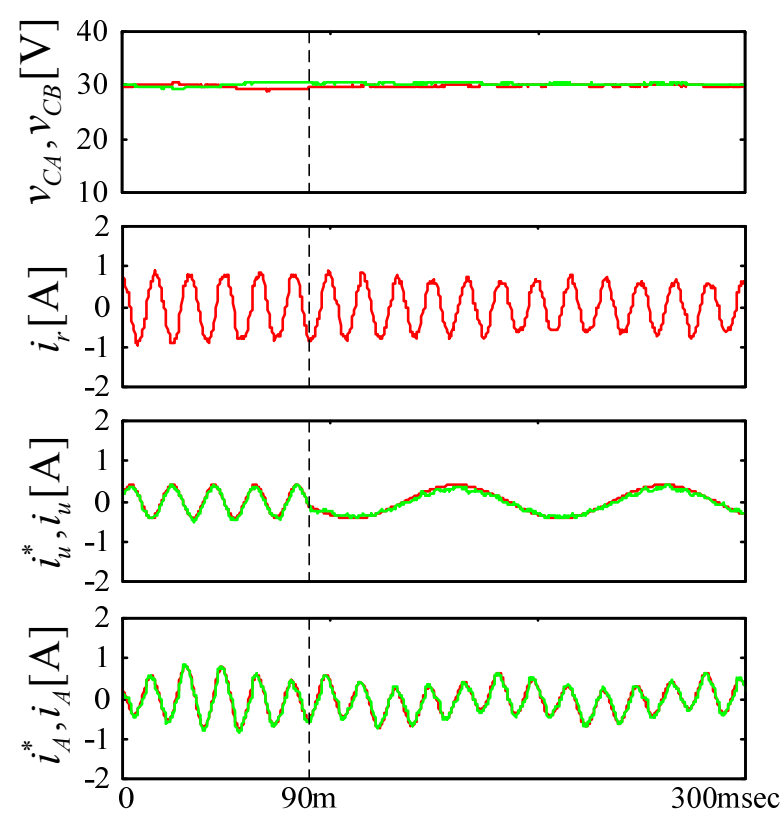

Fig. 10. Experimental result $\left(f_{1}: 60 \mathrm{~Hz}, f_{2}: 50\right.$ to $\left.10 \mathrm{~Hz}\right)$

wave is executed by the FPGA (Xilinx : XC3S15004FG456C). Switching frequency of each cell is $10 \mathrm{kHz}$ and sampling period of DSP is $100 \mu$ s in the experiment.

Fig.9 shows an experimental result that input frequency is $60 \mathrm{~Hz}$ and output frequency is $50 \mathrm{~Hz}$. Voltage of each floating capacitor is maintained to be constant value around $30 \mathrm{~V}$. Current of primary side, secondary side and arm module can be outputted accurately. Current of arm module is precisely regulated by the internal model principle in spite of mixed frequency. This behavior is very similar to the simulation.

Fig.10 shows an experimental result that input frequency is $60 \mathrm{~Hz}$ and output frequency changes from $50 \mathrm{~Hz}$ to $10 \mathrm{~Hz}$ by step. Output current in secondary side changes smoothly and regulated correctly. Voltage of capacitor keeps constant around 30V without influence of change.

Experimental results clarify that the proposed control method for H-MMC is able to work correctly and has good performance for power flow and voltage regulation of floating capacitors.

\section{CONCLUSIONS}

This paper investigated a new control of Hexagonal MMC for 3-phase BTB system. The H-MMC is applied to grid connection system and proposed how to control the power flow in primary and secondary side and the floating capacitor voltage of the H-MMC. In the H-MMC, sinusoidal currents with mixed frequency are controlled directly by using the internal model principle controller. The simulation and the experiment demonstrated that the proposed control method is able to control exactly and have a good performance. We intend to increase the number of cell of the experimental system and test in the near future.

\section{ACKNOWLEDGMENT}

This work was supported by JSPS KAKENHI (Grantin-Aid for Young Scientists(B)) Grant Number 24760237.

\section{REFERENCES}

[1] M. Hagiwara, H. Akagi, "Control and Experiment of PulsewidthModulated Modular Multilevel Converters", IEEE Trans. on PE, Vol.24, No.7, pp.178-1746, 2009.

[2] M. Hagiwara, R. Maeda, and H. Akagi, "Theoretical Analysis and Control of the Modular Multilevel Cascade Converter Based on Double-Star Chopper-Cells (MMCC-DSCC)"'(in Japanese), IEEJ Trans. on IA, Vol.16, No,.1, pp.8142, 2011.

[3] M. Glinka, R. Marquardt, "A New AC/AC Multilevel Converter Family”, IEEE Trans. on IE, Vol.52, No.3, pp. 66169, 2005.

[4] R.Marquardt,"Modular Multilevel Converter:An universal concept for HVDC-Networks and extended DC-Bus-applications",The Internationa Power Electronics Conference(IPEC),pp.502-507,2010.

[5] H. Fujita, M. Hagiwara, H. Akagi, "Power Flow Analysis and DCCapacitor Voltage Regulation for the MMC-DSCC"(in Japanese), IEEJ Trans. on IA, Vol.17, No.6, pp.659-665, 2012.

[6] W. Kawamura, H. Akagi, "Control Strategy of a Modular Multilevel Cascade Converter Based on Triple-Star Bridge-Cells (MMCC-TSBC)"(in Japanese), The Institute of Electrical Engineers of Japan, 1-14, pp.241-246, 2012

[7] L. Baruschka, A. Mertens, "A new 3-phase AC/AC modular multilevel converter with six branches in hexagonal configuration", Energy Conversion Congress and Exposition (ECCE), pp.40054012, 2011

[8] T. Hosaka, K Akiba and H Fujita, "A Unified Power-flow controller Consisting of Six Cascaded H-Bridge Converters" (in Japanese), The Institute of Electrical Engineers of Japan, 1-35, Vol.1, pp.233-236, 2011

[9] S. Hamasaki, K. Okamura, M. Tsuji, "Power Flow Control of Modular Multilevel Converter based on Double-Star Bridge Cells Applying to Grid Connection", Journal of ICEMS,Vol.2, No.2, pp.248-255, 2013

[10] S. Fukuda, T. Yoda "A Current Control Method for Active Filters Using Sinusoidal Internal Model” (in Japanese), T.IEEJ, Vol.120D, No.12, pp.111-146, 2000

[11] S. Hamasaki, M. Tsuji, E. Yamada "A Study on Power Flow Control for Distributed Generator with EDLC", SYMPOSIUM ON POWER ELECTRONICS, ELECTRICAL DRIVES, AUTOMATION AND MOTION (SPEEDAM), Vol.1, pp.1502-1507, 2010. 